\title{
UTILIZING MOBILE SENSING TO INVESTIGATE THE EFFECTS OF URBAN SPACE ON USERS BEHAVIOR
}

\author{
I. H. Hijazi ${ }^{a^{*}}$, R. El Meouche ${ }^{\mathrm{b}}$, A. Khan ${ }^{\mathrm{c}}$, N. Aboud ${ }^{\mathrm{a}}$ \\ ${ }^{a}$ An-Najah National University, Urban Planning Engineering, Nestablus, Palestine- eehab@najah.edu \\ ${ }^{\mathrm{b}}$ Université Paris-Est, Institut de Recherche en Constructibilité, ESTP, F-94230, Cachan, France - relmeouche@adm.estp.fr \\ c Karakoram International University, Pakistan - aftabhunzai@gmail.com
}

Commission VI, WG VI/4

KEY WORDS: Space syntax, Mobile sensing, GPS, Human behaviour

\begin{abstract}
:
Space syntax theory was used by many researcher to determine the correlation between people behaviour and urban configuration. However, The data collected for these studies using traditional data collection methods such as questionnaire and interviews, this is associated with inaccurate and biased in data. Wireless devices and smart phones and their sensing capabilities now can be involved in solving several issue. Many mobile applications have been developed with which people are able to keep track of their daily life details. In this research mobile sensing is used to track the location and activities of users in university campuses, the collected data is correlated to space properties to interfere the open space effects on student activities in a university campus. The paper utilize Mobile GPS and accelerometer sensors to sense people behaviour in urban configuration.
\end{abstract}

\section{INTRODUCTION}

Wireless devices and smart phones and their sensing capabilities now can be involved in solving several issue. Many mobile applications have been developed with which people are able to keep track of their daily life details. In this research mobile sensing is used to track the location and activities of users in university campuses and correlate it to space properties in order to determine the correlation between people activities and space properties.

This paper uses mobile sensing to track the location and activities of users in university campuses. The aim is analyzing open spaces uses i.e. particularly squares in university campuses, to the relationship to their users physical and movement patterns. It considers the design features of urban open space, focusing on student's activities and various forms of use. This problem forms the main reason to clarify, evaluate and analyze the relationship between physical patterns and student's activity patterns within open spaces in campuses. Therefore two questions would be answered through the paper:

- How do student's movement relate to the physical features of an open space?

- How mobile sensing and GIS analysis can be used for architectural studies

Number of students are asked to download the in house developed android mobile application. The mobile phone location information are used to determine the location of these students through campus and their motion by observing the changing locations of single mobile phones over time. Also using accelerometer we determine the movement pattern. These information is stored locally on mobile and then sent to the server, the received data then entered in GIS software to study the correlation between the collected values and isovsit field parameters of the urban configuration to determine the effects of urban configuration on people activities in the urban space and understanding the movement and activity patterns and the main factors influencing people to exist in a space or do a specific action.
These information would be helpful in determining the features or the specifications of such spaces with more students around, and to relate between each activity and the characteristics of the space. mobile sensing provide more accurate results of students movements and activates, compared to the direct observation or questionnaires which depend on the human factor.

\section{BACKGROUND}

(Campos and Golka 2005)Investigates the relationship between visual fields and patterns of stationary activity in several London public spaces. To meet this objective, visibility graph analysis, overlapping point isovists, and convex isovists methodologies were used. Correlation between the static activity patterns and visual fields showed that stationary activity is more likely to happen in relatively segregated spaces offset from the main access points. Also it shows that people selected more secluded areas compared to the exposed ones for informal static activities.

(Koohsariabc, et al. 2014)They briefly introduces the principles of space syntax and describes how space syntax can study the relationship between the built environment and physical activity research on parks and public open spaces. The study concludes that the methods and principles of space syntax offer several advantages to researchers studying the spatial properties of urban spaces. Nevertheless, it has some limitations. For example, it doesn't take into account land use and it deals with street configuration.

(SCHWANDER, KOHLERT and ARAS 2012) tries to put a benchmarking system for university campuses by comparing the design of two new campuses. This article focus on the spatial configuration of two different campuses of new universities that are built with an interconnected university model with the intention to foster meetings and informal communication of people. The study shows that the two campuses perform very differently in terms of spatial indicators although they are developed on the same design brief. At the macro scale, the study explores to what extent the campus is integrated into the urban fabric and has the potential for exchange with the local 
economy. At the micro scale it assess, if the internal spatial structure of the campus contributes to the objective of knowledge exchange across departments. For the micro-scale three analysis methods was employed: Topological network analysis, visibility graph analysis and agent analysis. The two different campus concepts result in a different user pattern: A relatively wide courtyard with large landscaping features and distributed entrances in the case of Hamm results in spread out movement over the entire campus. A compact courtyard with smaller landscaping features and centralized entrances leads to a concentrated movement pattern. However, this study lacks the analysis in the operational phase which could differ the results.

The above studies address how the spatial organization of a university campus influences the use of open spaces that have the potential to influence different types of interactions among people.

These researches investigate the relation between spaces and changing movement patterns by quantitative methods. In this paper, besides using space syntax theory, a mobile software app will be used to produce plans and maps for activity and students movements and location, to give more accurate results in addition to the survey and observation.

A rethinking on what kind of public practices are experienced in open spaces which have different physical and spatial characteristics may help us better understand the role of campus layout and its relation to different dimensions of a vivid public life.

\section{ONGOING WORK AND OUTLOOK}

An important step in this study is the development of the mobile application. Until today, The mobile application prototype is developed. The mobile app interface is composed from simple interface and it is starting collecting the mobile user location based on time interval defined by the user, also the accuracy of each collected point is stored. The aim is to allow filtering of the data to the points where accuracy is less than 10 meters. oreover, the current mobile app utilize the accelerometer to collect data that allow to know the users moving pattern. The current mobile app also contains functions that are required to transfer the data to a DBMS. Currently we are testing the ability of the mobile app to collect the required data. Future steps will include collected data and investigate if there is a correlation between the collected data and the space syntax parameters that will be extracted using GIS software. (Figure 1)

\section{EXPECTED RESULTS}

The results of space syntax analysis will be compared with the mobile sensor results in order to come out with the results and conclusion to this research.

Therefore, the value of this research is in studying the relationship between the activities and the physical settings of urban public spaces through using the proposed methodology. spatial analysis of the open space and using mobile sensing. Such research will help finding out why some urban spaces work while others don't. Analyzing this relationship will add insights into and complement the application of urban design theories and practice which could lead to further studies to improve the existing open spaces design and provide data and guidelines to new campus area design. Moreover, it will highlight how spatial analysis techniques and mobile sensing can be used in architecture and urban design

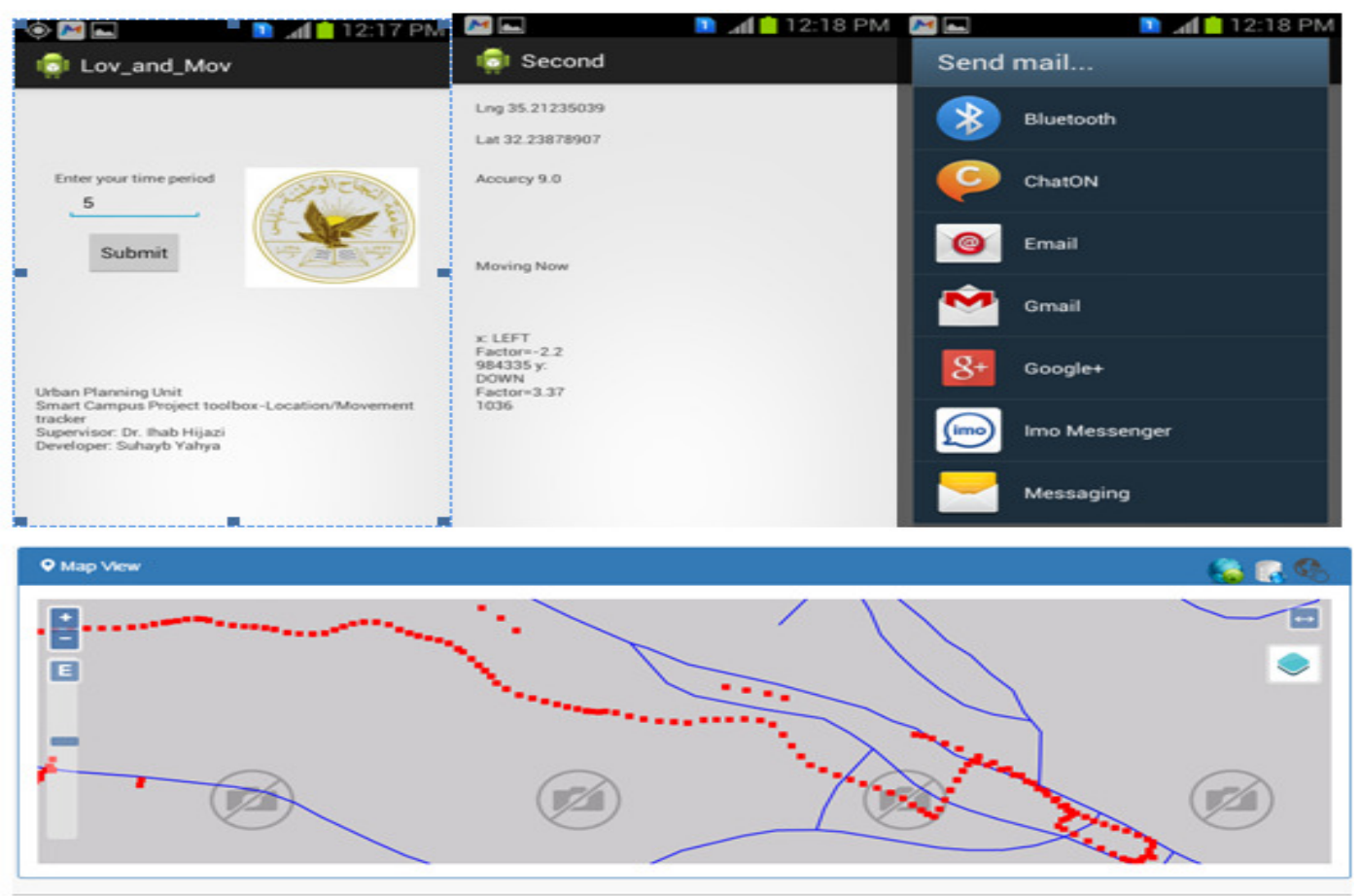

Figure 1. Mobile App interfaces and Data Visualization 


\section{REFERENCES}

Hattori, K., and Masatoshi N. 2010. The Study of the Visual Value of Open Space on a University Campus. Policy \& The Environment edra 41. 2010. pp. 82-89.

Heitor, T V., Ana, T., Paulo, Dimas. João P. S. 2007.

Synchronizing Spatial Information Complex Environments: a crossover of space syntax and spatial information visualization. Proceedings 6th International Space Syntax Symposium. İstanbul,.pp. 098-18.

Koohsariabc, M. J. , Andrew T. K., Gavin R. M., and Takemi S. 2014. Using Space Syntax to Assess the Built Environment for Physical Activity: Applications to Research on Parks and Public Open Spaces. An Interdisciplinary Journal. pp. 206-216.

Leisure Sciences:

Lau. S. S. Y., Zhonghua G., and Yajing., Liu. 2014. Healthy campus by open space design: Approaches and guidelines. Frontiers of Architectural Research. pp. 452-467.

Rasouli, M., 2013. Analysis of Activity Patterns and Design Features Relationships in Urban Public Spaces Using Direct Field Observations, Activity Maps and GIS Analysis Mel Lastman Square in Toronto as a Case Study. The Univesity of Waterloo. 